\title{
Behavior of Stem-Like Cells, Precursors for Tissue Regeneration in Urodela, Under Conditions of Microgravity
}

\author{
Eleonora N. Grigoryan and Elena A. Radugina
}

\begin{abstract}
We summarize data from our experiments on stem-like cell-dependent regeneration in amphibians in microgravity. Considering its deleterious effect on many tissues, we asked whether microgravity is compatible with reparative processes, specifically activation and proliferation of source cells. Experiments were conducted using tailed amphibians, which combine profound regenerative capabilities with high robustness, allowing an in vivo study of lens, retina, limb, and tail regeneration in challenging settings of spaceflight. Microgravity promoted stem-like cell proliferation to a varying extent (up to 2-fold), and it seemed to speed up source cell dedifferentiation, as well as sequential differentiation in retina, lens, and limb, leading to formation of bigger and more developed regenerates than in $1 \mathrm{~g}$ controls. It also promoted proliferation and hypertrophy of Müller glial cells, eliciting a response similar to reactive gliosis. A significant increase in stem-like cell proliferation was mostly beneficial for regeneration and only in rare cases caused moderate tissue growth abnormalities. It is important that microgravity yielded a lasting effect even if applied before operations. We hypothesize on the potential mechanisms of gravity-dependent changes in stem-like cell behavior, including fibroblast growth factor 2 signaling pathway and heat shock proteins, which were affected in our experimental settings. Taken together, our data indicate that microgravity does not disturb the natural regenerative potential of newt stem-like cells, and, depending on the system, even stimulates their dedifferentiation, proliferation, and differentiation. We discuss these data along with publications on mammalian stem cell behavior in vitro and invertebrate regeneration in vivo in microgravity. In vivo data are very scarce and require further research using contemporary methods of cell behavior analysis to elucidate mechanisms of stem cell response to altered gravity. They are relevant for both practical applications, such as managing human reparative responses in spaceflight, and fundamental understanding of stem cell biology.
\end{abstract}

Keywords: regeneration, microgravity, stem-like cells, proliferation, dedifferentiation, amphibians

\section{Introduction}

$\mathrm{S}$ TUDYING BEHAVIOR OF stem cells during spaceflight and $\checkmark$ in simulated microgravity is necessary to foresee how human stem cells, which represent the primary source of our regeneration, will respond to spaceflight in vivo; it is also necessary to support biotechnological assays. Research in this area utilizes a wide range of cell models, most common being cultured human or rodent stem cells. Taken together, results show the effects of real and simulated microgravity on stem cell migration, proliferation, and differentiation-key processes in tissue development and regeneration [1-7]. Original hardware is being developed to conduct such experiments onboard spacecrafts and in laboratories, and new ways of utilizing methods of cell culture in microgravity, as well as cells themselves, in bioengineering and regenerative medicine are being proposed [8,9]. Some researchers also study the effects of space radiation, which is inherent to spaceflight experiments, on various in vitro systems, including stem cells [10].

Effects of microgravity on stem cells not only depend on cell type but also vary between experiments. Blaber et al. [7] demonstrated that murine embryonic stem cells in an original cell culture module onboard space shuttles maintained their stem state, but were less likely to differentiate. Their differentiation was also altered in simulated microgravity in a $2 \mathrm{D}$ pipette clinostat [11]; rotation in a $3 \mathrm{D}$ clinostat $\left(10^{-3} \mathrm{~g}\right)$ led to a decrease in proliferation and adhesion, and it increased cell death [12]. The study of embryonic stem cells is included in a broad research program onboard ISS/Kibo facility, which is expected to provide new results in the near future [13].

Human pluripotent stem cells (IMR90 iPSCs, H7 and H9 embryonic stem cells cell lines) differentiating into cardiomyocytes in $3 \mathrm{D}$ culture survived and divided better in

Koltzov Institute of Developmental Biology of Russian Academy of Sciences, Moscow, Russia. 
simulated microgravity, which was also reflected in the upregulation of corresponding genes [14].

Neural stem cells isolated from rat telencephalon tissues cultured in an automated bioreactor onboard SJ-10 satellite maintained their potential and displayed a transcription profile similar to that of the control, but they tended to divide less and were more prone to enter neuronal differentiation [15]. Interestingly, neural stem cells exposed to microgravity tended to differentiate into astrocytes on transplantation [16].

Mesenchymal stem cells are the most widely used in microgravity experiments, as they provide clues for managing bone and muscle maintenance, which is a major concern in spaceflight $[17,18]$. Results vary significantly due to differences in cell extraction and culture protocols, hardware, and general experimental approach, but in all cases microgravity proves to have an effect on some aspect of mesenchymal stem cell biology [1-5,9,19-22]. In particular, simulated microgravity has been reported to inhibit cell migration in vitro [23] and to affect differentiation by generally broadening cell potential [24] or promoting differentiation toward force-insensitive adipocytes, as opposed to force-sensitive cardiomyocytes and osteoblasts [25]. The effects might be time-dependent: Mesenchymal stem cells exposed to simulated microgravity for $72 \mathrm{~h}$ underwent endothelial, neuronal, and adipogenic differentiation, whereas after 10 days they became osteoblasts [26].

So far, it has been difficult to draw solid conclusions from these results, much less to propose a complete chain of molecular events from perception of microgravity to altered stem cell behavior. However, generally discussed mechanisms include mechanosignaling, mechanotransduction, and oxygen influence, as reviewed by Bradamante et al. [27]. It is also clear that these mechanisms end up altering the expression of genes that control stem state, cell proliferation, and differentiation, for example, changes in the RhoAassociated pathway played a role in time-dependent differentiation [26], and OCT4 (stem cell marker and a member of "pluripotency cocktail") was upregulated in the case of broadened differentiation potential [24].

In vivo studies of stem cell behavior in microgravity are much more scarce: Utilized models include planarian neoblasts [28] and murine satellite cells [29]. The latter are particularly important, as they are considered to play a crucial role in muscle fiber maintenance, repair, and remodeling [30], whereas muscle atrophy is among the bestknown negative effects of microgravity [31-35].

In our experiments, we focused on stem-like cells that provide a source for eye, limb, and tail regeneration in lower vertebrates (newts) (Fig. 1). Despite being evolutionary rather distant from humans, newts offer the invaluable possibility to investigate the effects of real and simulated microgravity (including prolonged ones) on stem-like cells in vivo, and also to compare responses of different populations of stem-like cells contained within the same gravity unloaded organism. This review summarizes results of years of our research on newt regeneration onboard Russian biosatellites and Foton science satellites, as well as in simulated microgravity. We have been able to standardize most of the conditions, using highly homogenous animal groups (in terms of age, sex, lineage), similar experimental protocols (with minimal variations to fit specific tasks), uniform op-

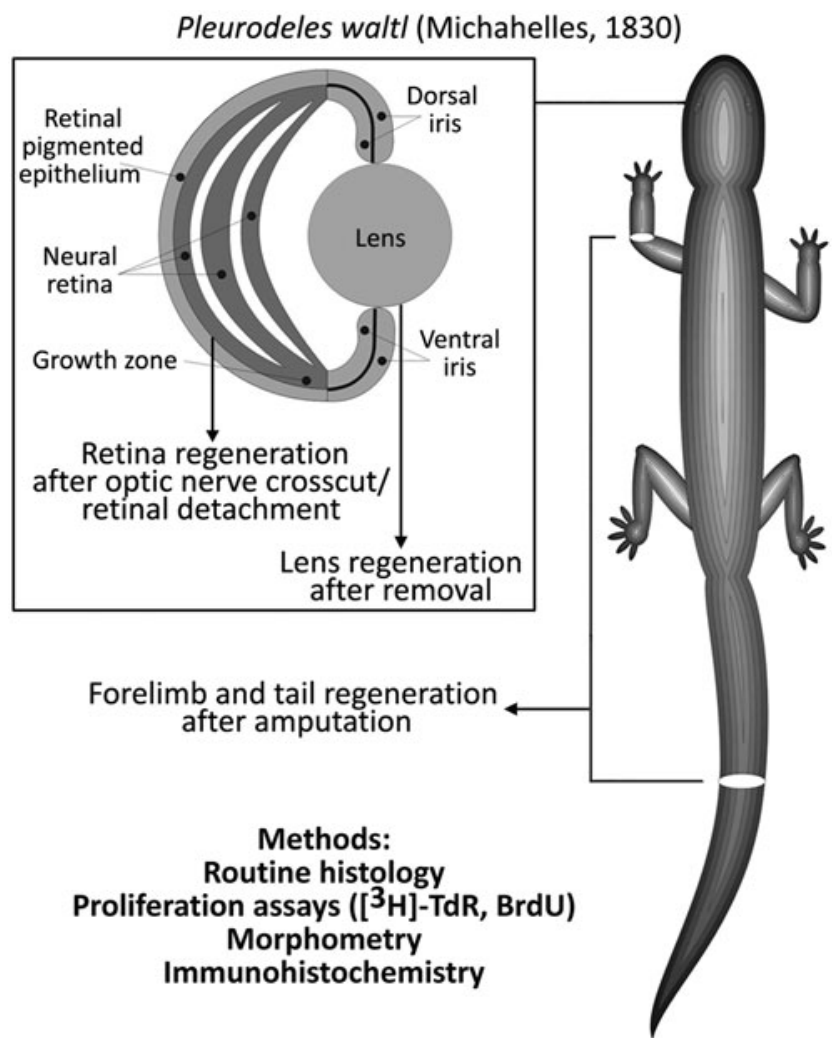

FIG. 1. Object, methods, and models of regeneration used in spaceflights, simulated microgravity experiments, and ground controls.

eration technique, animal handling practices, and in-flight maintenance systems. In all spaceflight experiments, a group of animals (referred to as "flight group") exposed to microgravity in a special humidified chamber equipped with gas exchange filters ("Triton" container) onboard a satellite was compared with several controls: basal control-animals that were fixed at the day of launch, representing the state before exposure to microgravity; aquarium controlanimals that underwent the same procedures as the flight group, but were kept in water-filled aquarium in the lab instead of being sent to space (ie, maintained in normal conditions); synchronous control-animals that underwent the same procedures and were kept in the same chambers as the flight group, but stayed in the special room in the lab (conditions such as temperature being adjusted to those reported by satellite sensors as they became available-hence the name "synchronous"). Participation in 12 flight experiments allowed us to build up a body of reproducible and credible results (Table 1).

\section{Iris pigmented epithelium cells}

Lens regeneration in newts, which occurs via transdifferentiation of iris pigmented epithelium cells (IPECs), is a classical example of natural reprogramming, one of the very few in vertebrates. It has been studied comprehensively by a wide range of means, from earlier morphological observations to modern molecular approaches [36-39]. After lens removal, IPECs lose their original traits (such as epithelial 
Table 1. Missions and Some Characteristics of Animals: Newts (Pleurodeles Waltl; All Missions Except Bion M1) and Mice (C57BL/6N SPF; BION-M1 Mission)

\begin{tabular}{lccccrr}
\hline Mission & Year & Flight, days & Total N/dead & Age $\mathrm{a}^{\mathrm{a}}$ & Weight, $g$ & Length, cm \\
\hline Cosmos-1667 & 1985 & 7 & $30 / 0$ & 10 & $10.0-11.0$ & $9.5-10.0$ \\
Cosmos-1887 & 1987 & 13 & $70 / 8$ & 6 & $6.5-7.0$ & $10.0-11.0$ \\
Foton-4 & 1988 & 14 & $30 / 0$ & 7 & $6.5-7.0$ & $11.0-12.0$ \\
Foton-5 & 1989 & 15 & $30 / 0$ & 2 & $4.6-5.0$ & $7.0-8.0$ \\
Cosmos-2044 & 1989 & 14 & $55 / 0$ & 2 & $4.5-5.5$ & $7.0-8.0$ \\
Foton-6 & 1990 & 16 & $67 / 5$ & 3 & $5.0-6.0$ & $8.0-9.0$ \\
Foton-7 & 1991 & 16 & $65 / 0$ & 11 & $10.5-11.0$ & $12.5-13.0$ \\
Cosmos-2229 & $1992-1993$ & 12 & $45 / 9$ & 12 & $11.0-12.0$ & $15.0-17.0$ \\
Bion-11 & $1996-1997$ & 14 & $30 / 0$ & 12 & $8.5-9.5$ & $12.0-13.5$ \\
Foton-M2 & 2005 & 16 & $45 / 1$ & 6 & $5.5-6.5$ & $9.0-10.0$ \\
Foton-M3 & 2007 & 12 & $50 / 0$ & 7 & $6.5-7.5$ & $11.0-12.0$ \\
Bion-M1 & 2013 & 30 & $28 / 0$ & $8-9$ weeks & $25.0-30.0$ & $10.0-15.0$ \\
\hline
\end{tabular}

${ }^{\mathrm{a}}$ For newts-months after metamorphosis.

morphology and pigment), proliferate, produce a population of blastema cells, form early lens, regenerate, and differentiate into lens epithelium cells and lens fibers as they mature $[40,41]$.

Although not known to possess or acquire multipotency, during dedifferentiation these cells display a change in gene activity, reaching a state that resembles that of stem cells $[42,43]$. Some authors insist that dedifferentiated IPECs should be considered stem-like: sox2, klf4, c-myc-genes that constitute Yamanaka's "pluripotency cocktail" [44]_ are expressed during IPECs reprogramming, although their counterparts oct4 and nanog are not [45]. Other "immature" traits of IPECs during reprogramming include increased levels of "embryonic" B4 histone [46] and nucleolar accumulation of nucleostemin [47], a protein common for mammalian stem and cancer cells [48].

Speed and efficiency of IPEC conversion during lens regeneration could be affected, aside from chemical means, by environmental factors such as temperature or irradiation [49-51]. They are also notably increased in spaceflight, as demonstrated in multiple experiments onboard Russian Bion/Foton satellites.

An increased number of dedifferentiated, proliferating IPECs in de novo lens (compared with ground control) was noted in 7-day-long Cosmos-1667 flight in 1985 [52]. Detailed analysis using tritiated thymidine radioautography $\left(\left[{ }^{3} \mathrm{H}\right]-\mathrm{TdR}\right)$ was carried out during Cosmos-1887, Cosmos2044, and Foton-7 flights [53-55] and confirmed increased proliferation in lens-forming IPECs, as well as in other stem-like cells in retina and iris growth zones (ora serrata, pars ciliaris) (Fig. 2B). Proliferation level in lens regenerate cells was increased after landing, compared with control, and the difference pertained for $\sim 2$ weeks (Fig. 2C). A sixteen-day-long experiment onboard Foton 7 satellite confirmed these observations and demonstrated that stimulation of stem-like IPECs, leading to formation of bigger, more developed regenerates, occurs not only in animals operated before the flight but even in those whose eyes were intact during flight and operated after its completion (Fig. 2A) [56].

All these results-increased stem-like cell proliferation (measured by incorporation of $\left[{ }^{3} \mathrm{H}\right]-\mathrm{TdR}$ and bromodeoxyuridine $[\mathrm{BrdU}])$, enlarged lens regenerates, and prolonged effect—were reproduced in simulated microgravity by using a fast-rotating clinostat at Cologne University, Germany [57], so we are confident that microgravity (real or simulated) is the major factor modifying IPECs behavior. In one case, a tumor developed from rapidly growing and partially depigmented IPECs, suggesting that the stimulatory effect of microgravity might be excessive and disturbing for lens morphogenesis (Fig. 3). It should be stressed that although organ morphology was flawed, individual cells kept their original phenotype and were not malignant, and so the event could not be classified as cancer (to which newts, especially their regenerative-competent tissues, are famously resistant [58]).

Taken together, these data suggest that the prolonged stimulating effect of microgravity on stem-like cells is mediated by lasting systemic changes. We considered various systemic, exo- and intracellular molecules that could be potentially involved in such changes [59,60], including complement components [61], Wnt [62] and Shh signaling pathways [63]. However, due to the inherent complexity of stem-like IPECs activation mechanisms, as well as spaceflight limitations, we focused on fibroblast growth factor 2 (Fgf2) - a major player in lens formation, capable of inducing a second lens formation on exogenous administration $[64,65]$. In Foton-M3 experiment in 2007, we showed that an increase in Fgf2 expression, which accompanies IPECs proliferation, was more prominent in spaceflight than in ground control, and so was the immunostaining against chaperone Hsp90 [66]. The latter may influence a wide spectrum of processes, including signal transduction, chromatin remodeling, proliferation, and apoptosis, and is known to respond to trauma, ensuring cell survival [67].

Microgravity results were complemented with data from the hypergravity experiment at NASA Ames Research Center, during which lensectomized newts were exposed to $2 \mathrm{~g}$ for 12 days in an 8-ft diameter centrifuge. Lens regeneration was retarded and desynchronized in this setting (with regenerates reaching stages II-IX compared with stages VII-IX in $1 \mathrm{~g}$ control) [68] - a direct opposite to what was observed in microgravity. Retinal detachment was prevalent and localization of Fgf2 and its receptor was altered in $2 \mathrm{~g}$ eyes, probably accounting for impaired lens regeneration.

In conclusion, multiple experiments demonstrate that real and simulated microgravity has strong and prolonged 
FIG. 2. Stimulatory effect of spaceflight on lens regeneration. (A) Size of lens regenerates in animals operated before and after spaceflight onboard Foton-7. (B) Proliferation rates in lens regenerates and eye growth zones of lensectomized newts, measured by $\left[{ }^{3} \mathrm{H}\right]$-thymidine incorporation after Cosmos-2044 spaceflight. (C) Mean indices of $\left[{ }^{3} \mathrm{H}\right]$-thymidine-labeled nuclei in lens regenerates of the flight group divided by respective control value for several spaceflights. Numbers in parentheses are days: between operation and take-off; in microgravity; between landing and fixation. All measurements were made for six samples per group. $\left[{ }^{3} \mathrm{H}\right]$-thymidine-labeled cells were counted in every second section over a complete series and summarized to get an individual sample's value. Boxes-mean values, error bars-standard deviation.

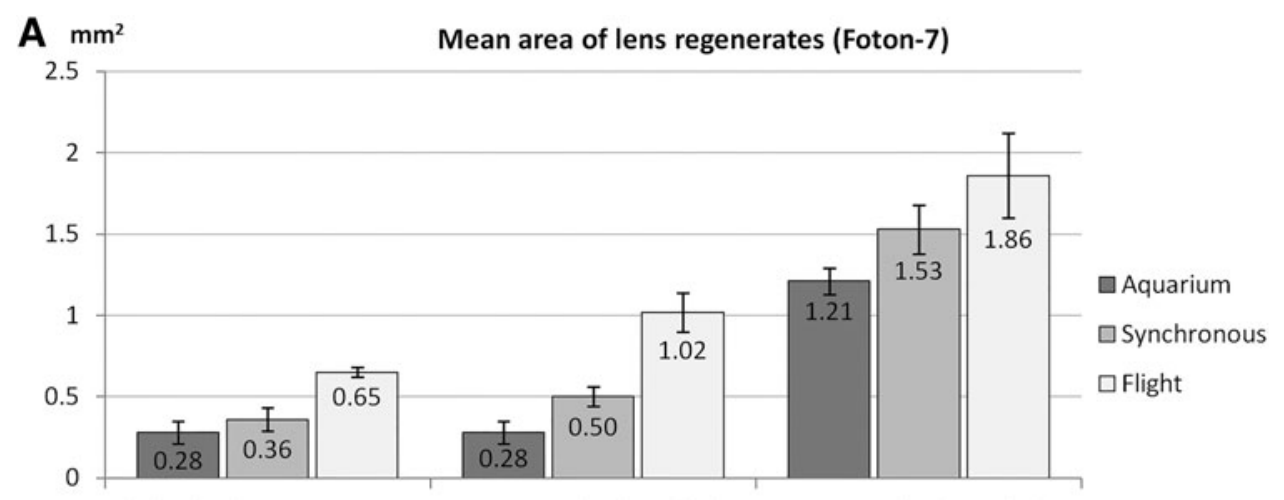

Flight before operation, Operation before flight, Operation before flight, fixed at $23 \mathrm{dpo} \quad$ fixed at $23 \mathrm{dpo} \quad$ fixed at $33 \mathrm{dpo}$

B \% Indices of $\left[{ }^{3} \mathrm{H}\right]-\mathrm{TdR}$ labeled nuclei in different eye zones

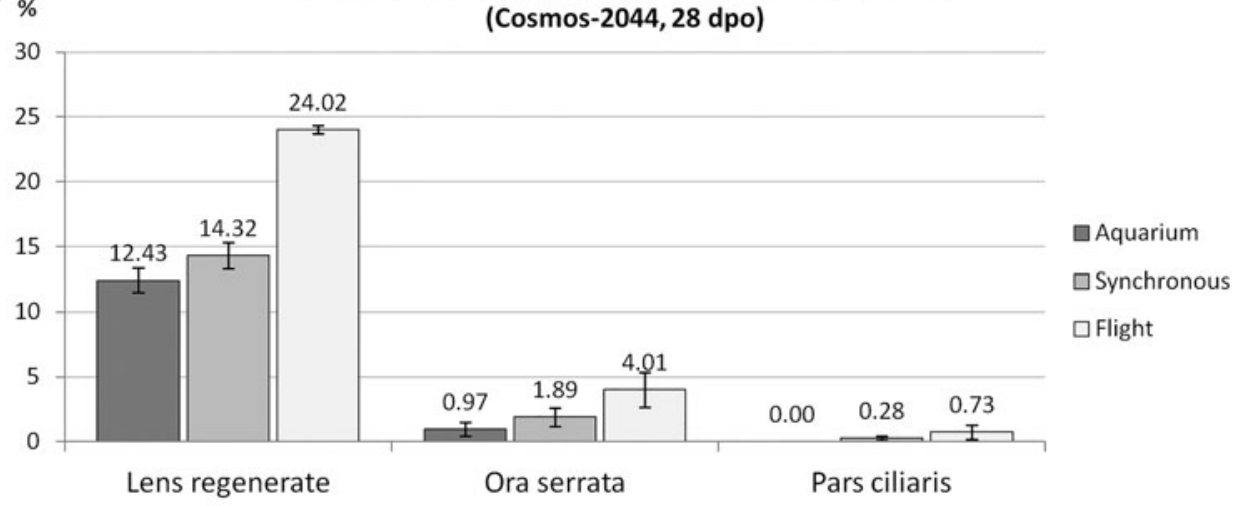

C
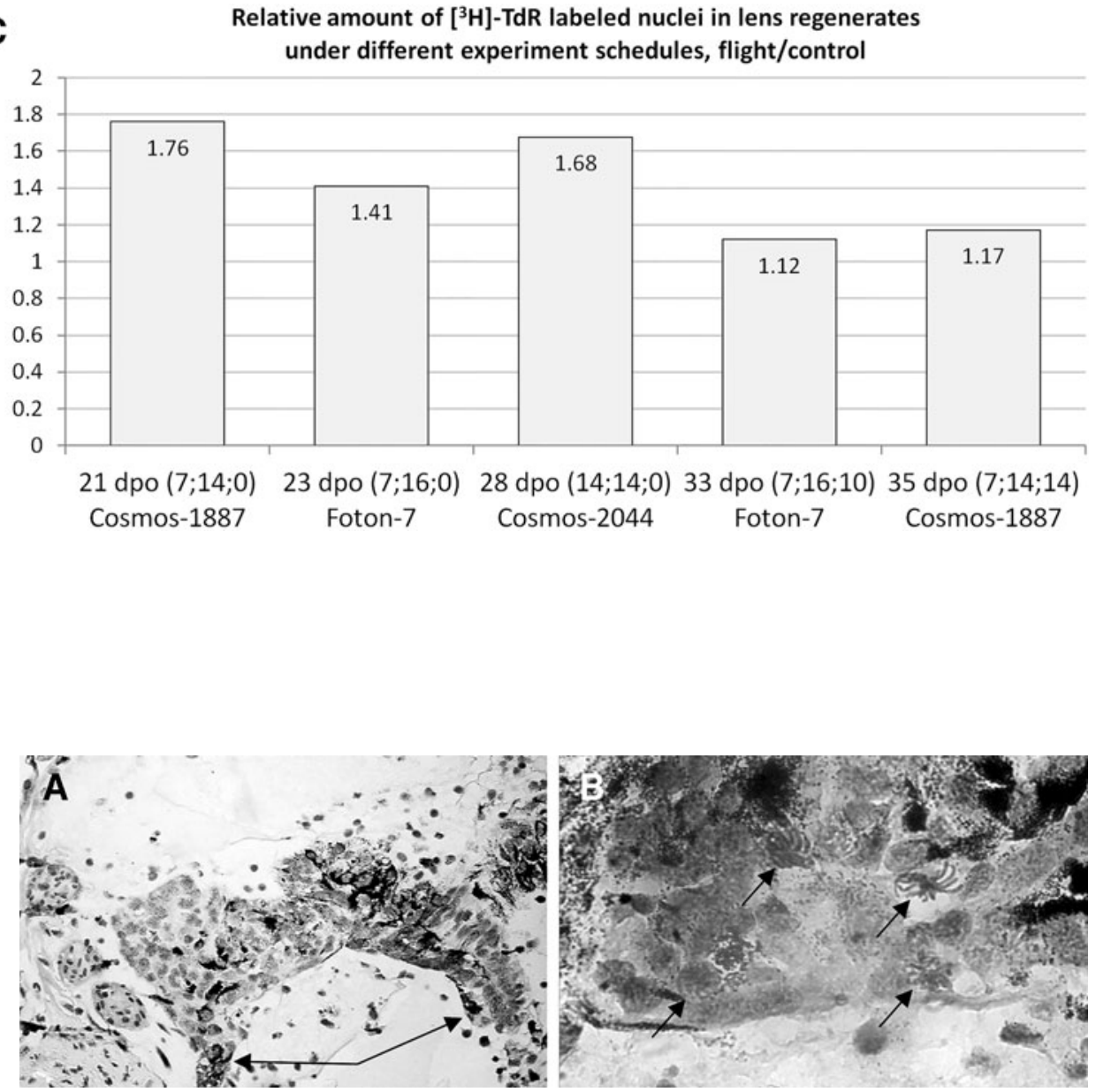

FIG. 3. Morphogenetic changes induced by "overproliferation" of iris stem-like cells during lens regeneration in newts exposed to simulated microgravity: overgrown dorsal edge of the iris, $200 \times($ A); multiple mitoses in the dorsal edge of the iris (arrows), $1,000 \times(\mathbf{B})$ 
stimulatory effect on stem-like cells involved in lens regeneration, whereas hypergravity acts as their inhibitor. These effects are most likely systemic, and they could be mediated by various factors: Fgf2 signaling pathway, heat shock proteins, and others that are yet to be determined.

\section{Retinal pigmented epithelium cells}

Retinal pigmented epithelium lies between eye choroid coat and neural retina, serves multiple boarder functions, and participates in light perception [69]. On injury or removal of the retina in adult newts, retinal pigmented epithelium cells (RPECs) divide and transdifferentiate into neurons and glia, forming structurally complete and functional regenerate [70-73].

Despite being obviously specialized, newt RPECs display a "young," stem-like gene expression profile [74]. Markers of specialization (rpe65, otx2, mitf) are expressed in these cells along with early development "eye field" genes ( pax6, pitx1, hes1). Retinal and IPECs share a number of other stem-like traits, including nucleolar localization of nucleostemin [75]. Expression of pluripotency factors has not been assessed in newt RPECs; however, in chick SOX2, $C-M Y C$ and $K L F 4$, along with "eye field" genes, such as $P A X 6$, are upregulated early after retina removal, before the onset of proliferation [76].

Models for studying retinal regeneration in newts include retinal detachment, optic nerve and blood vessel crosscut, and retinal removal; we used the second one in our spaceflight experiments. Cutting nerve and vessels leads to massive cell death and retinal degeneration, which prompts RPECs to proliferate, undergo cell-type conversion, and form a population of multipotent proliferating cells that are capable of further differentiation into all types of retinal neurons and glia [71,77]. Eye growth zones (ora serrata, pars ciliaris) provide an additional source of undifferentiated cells. These processes were studied during the 14-daylong Bion-11 flight, featuring newts operated 2 weeks before the start. Proliferation of RPECs (measured by $\left[{ }^{3} \mathrm{H}\right]-\mathrm{TdR}$ labeling) was 1.2-1.5 times higher in flight than in ground control (Fig. 4); proliferation of cells in retinal growth zone was also increased [78]. Dedifferentiation, including loss of pigment, also proceeded faster in flight, possibly due to end of melanin synthesis and "dissolving" of existing granules through cell division. As a result, overall rate of retinal regeneration was higher in spaceflight compared with control.

Experiments using the retinal detachment model in newts were conducted in simulated microgravity $[79,80]$. Retinal detachment was achieved microsurgically: first; a lensectomy was performed, which caused a drop in intraocular pressure and subsequent initial detachment, which was further aggravated by delicately pressing along the limb zone with a glass stick until retinal folds were visible through the pupil. It was followed by morphological and functional restoration of the retina. In particular, the level of retinal cell apoptosis decreased whereas RPECs redifferentiation (turning back to the initial differentiation after partial depigmentation and the beginning of conversion) was much more successful than in ground controls, which allowed retinal reattachment in dorsal and central areas.

Our experiments on retinal regeneration after optic nerve crosscut and retinal detachment in newts showed that early steps of the process-proliferation and first steps of RPECs conversion-are positively affected by real and simulated microgravity. Research in this area remains scarce, and models are not always comparable. However, there are indications that the said effect is not limited to newts: Using a rotating-wall vessel bioreactor, which provides physiological weightlessness, for culturing retinal organoids from murine-induced pluripotent stem cells proved to be stimulatory, increasing cell proliferation, differentiation of all retinal cell types, rate of development, and size of the organoids compared with static culture [81].

We found no reports of other nonspecific physical factors having comparable effects on RPECs, but from our experience rate of their regeneration responses depend on newt species and age, and also on temperature and year season (which were all controlled in our microgravity experiments).

As in the case of IPECs, the complete chain of events linking microgravity with specific responses of RPECs is unknown. However, we find it likely to include generalized response on the level or organism, which, in turn, affects local regulatory mechanisms in different tissues with different results depending on local specifics [78]. In case of RPECs, these mechanisms have been well studied both in vivo and in vitro and recently summarized [82]. They involve Fgf2, Wnt, and Notch-Delta signaling pathways and

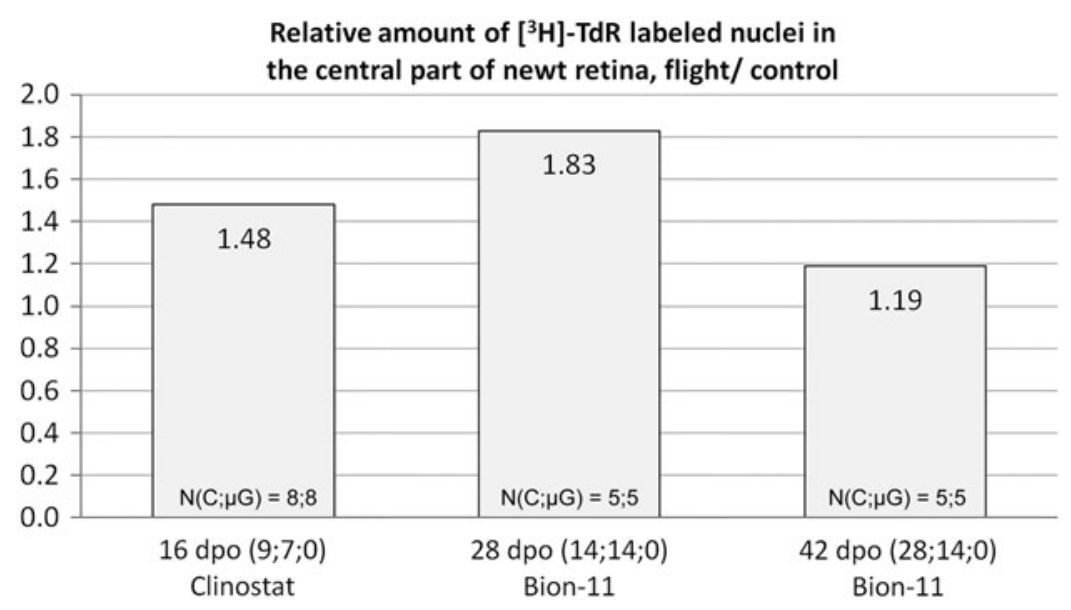

FIG. 4. Increased retinal pigment epithelium cell proliferation in microgravity: normalized indices of $\left[{ }^{3} \mathrm{H}\right]$-thymidine-labeled nuclei in the central part of neural retina regenerates obtained in Bion-11 spaceflight and clinostat experiments. Values calculated for microgravity groups (flight or rotation) were divided by those for controls (synchronous or fettered-kept in the same habitats as the respective experimental group). Numbers in parentheses are days: between operation and take-off; in microgravity; between landing and fixation. $\mathrm{N}(\mathrm{C} ; \mu \mathrm{G})$ indicates sample sizes in controls and microgravity groups, respectively. $\left[{ }^{3} \mathrm{H}\right]$-thymidinelabeled cells were counted in every second section over a complete series and summarized to get an individual sample's value. 
developmental transcription factors Pax6, Sox2, and Oct4all candidates for further investigation in microgravity experiments.

\section{Müller glia}

Müller glia (MG) is a retinal cell type carrying structural and neurotrophic functions, involved in retinal metabolism, clearance, and light perception, heavily interconnected with all types of retinal neurons (reviewed in Ref. [83]). They also represent a potential source of retinal regeneration in vertebrates, including humans [84-86]. On injury, fish MG cells can proliferate and redifferentiate into neurons [87]; the same has been shown for isolated mammalian MG cells in vitro [88]. In vivo mammalian MG usually replies to injury by reactive gliosis - rapid proliferation without change in cell identity, cellular hypertrophy, and increase of the thickness of accessory prolongations [83]. Reactive gliosis accompanies many pathological conditions, secreting neuroprotective factors and preventing glutamate neurotoxicity [89].

Apart from phenotype change abilities, represented to various extents depending on species and conditions, MG cells possess other stem-like traits: expression of early retinal progenitor markers [90], characteristic chromatin state and DNA methylation landscape [91], niche, closely resembling that of retinal stem cells [92]. Injury to fish retina prompts MG cells to undergo changes, similar to those accompanying induction of pluripotency in somatic cells, including expression of characteristic genes [93].
These cells are known to respond to certain physical factors: For example, genes associated with neurogenesis, as well as retinal neuron-specific genes, are differentially expressed in 2D and 3D differentiation conditions of murine MG cells [94]. MG stem-like cells of newt and rat retina can divide in roller 3D culture in the absence of mitogenic factors in the media $[95,96]$. Our experiments showed that MG cells of newt in vivo are also sensitive to real and simulated microgravity [97].

Microsurgical retinal detachment in newts caused growth of the MG population (assessed by the number of $\left[{ }^{3} \mathrm{H}\right]-\mathrm{TdR}-$ labeled MG cells and the number of their accessory prolongations), which was further increased by simulated microgravity, reaching a 1.5-2.0-fold difference with $1 \mathrm{~g}$ control after 7 days in clinostat $[79,97]$. Real microgravity onboard Bion 11 biosatellite also promoted MG amplification (40\% increase in a number of cells expressing its marker protein, Gfap) in newts regenerating retina 4 weeks after optic nerve crosscut [97,98]. Lensectomy led to increased immunostaining for both Gfap and stress protein Hsp90, which was more prominent in microgravity during Foton M3 spaceflight than in $1 \mathrm{~g}$ controls (Fig. 5) [66,97]. In cases where retina is not directly disturbed, MG cells may respond to changes in intraocular pressure (for example, its drop after lensectomy); laser-induced increase in intraocular pressure increases expression of GFAP in $\mathrm{MG}$ cells of rat retina in vivo [99]. Such $M G$ reactions might be clinically important for cosmonauts, because simulated microgravity [100], real microgravity in space [101] and rapidly

FIG. 5. Gfap expression in Muller cells of the newt retina during Foton-M3 experiment: typical example of immunostaining (long white processes in the inner portion of the retina) in synchronous $1 \mathrm{~g}$ control (A) and relative intensity of immunostaining in all groups (B), calculated for 20 sections derived from 4 eyes in each group. Asterisk indicates that the difference was found to be significant by Student's test with a $p$-level of 0.05 .
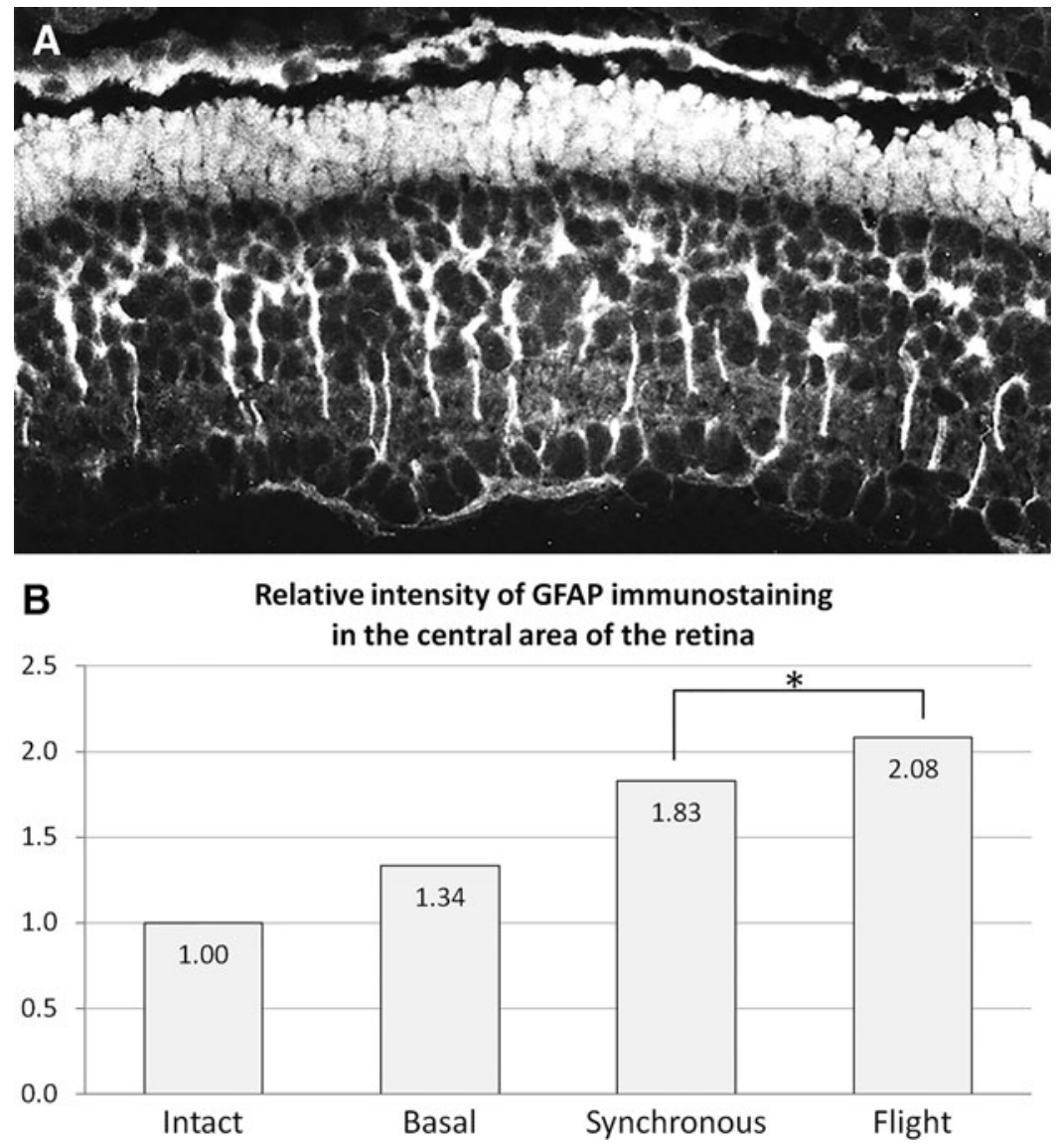
changing g levels [102] change intraocular pressure in humans.

We have not detected MG conversion in other cell types in newt retina in these conditions. Rather, MG response to microgravity resembled aforementioned reactive gliosis, comprising self-amplification, cellular hypertrophy, growth of accessory prolongations, and increased Gfap synthesis. It is worth noting that Gfap is a component of intermediate filaments, involved in nuclear translocation and cell division, so, rather than being a mere cell type marker, it is integral to MG damage response [103,104]. The same is probably true of Hsp90, which ensures cell survival under various stressful conditions [105].

To some extent, MG cells resemble neural stem cells [6], which have been studied in space conditions by other groups. Murine neural stem cells, cultivated in a 3D bioreactor in space, maintained their "stemness," even displayed upregulation of stem cell transcription factors Sox2 and Pax6, but proliferated slower than in $1 \mathrm{~g}$ and underwent neural differentiation more readily [15]. Global transcriptomic analysis revealed the leading role of the WNT signaling pathway in these processes. This pathway is also important for MG conversion and reactive gliosis. WNT3a induces proliferation of MG cells in rat retina explants in a dose-dependent manner, which can be prevented by inhibiting WNT receptors Frizzled-1 and CRD [106]. Keeping in mind the differences in cell types, species of origin, and settings (in vivo vs. in vitro), we can summarize that microgravity does not interrupt with stem state or block regenerative responses, but it can shift the balance between self-amplification and differentiation via a WNT-dependent mechanism.

\section{Limb and tail regeneration blastema}

Both limb and tail of adult newts regenerate completely on amputation via a similar sequence of events [107,108], most importantly, formation of blastema-proliferating mass of seemingly undifferentiated, mesenchymatous cells with large nuclei, prominent nucleoli, and well-developed endoplasmic reticulum. After several cell cycles, they differentiate and give rise to most tissues of de novo structure (except for nerves, vessels, and epidermis that develop di- rectly from their respective structures of the stump) [109]. Blastema cells can originate from dedifferentiated cartilage, muscle, connective tissue, and Schwann cells from the stump [110], as well as from tissue-specific stem cells [111], although exact contributions vary depending on species [112] and developmental stage [113].

Due to "embryonic" appearance and ability to generate missed structures, blastemal cell plasticity has been a burning issue since the beginning of the twentieth century (reviewed in Ref. [114-116]). Although not pluripotent [117], they are able to switch lineages: muscles and bone can regenerate from other sources when absent in the stump of the newt limb $[118,119]$, whereas muscle-derived blastema cells can themselves contribute to cartilage formation [120]; spinal cord cells migrate into blastema to form muscles and cartilage during tail regeneration in larval axolotl [121]. Under normal conditions, however, blastemal cells seem to redifferentiate primarily within their original lineage, connective tissue fibroblast-derived cells being the most labile of all [110].

Apart from their potential (whether or not it is normally fulfilled during regeneration) to switch lineages, dedifferentiating cells that form a blastema possess many stem-like features, such as nucleolar nucleostemin accumulation [47], extracellular matrix remodeling by decreased collagen II synthesis and fibronectin, tenascin, and hyaluronate accumulation [122-124], upregulation of transcription "progenitor" genes msxl, msx2, nrad, rfrng, and notch [125,126], and pluripotency genes klf4, sox2, c-myc, and lin 28 [45,127]. These features allow placing limb and tail regeneration precursor cells into the stem-like cell category.

Epimorphic regeneration after amputation. Tail and limb regeneration have been studied extensively in the experiments mentioned earlier; the broadest conclusion is that epimorphic regeneration proceeds in microgravity and is directly comparable to that in normal conditions. However, due to limitations inherent to in vivo studies, spaceflights, and also methodological opportunities of that time, limited conclusions could be drawn regarding cellular responses.

As with lens regeneration, microgravity accelerated limb regeneration in terms of both size and developmental stage; the effect was most prominent between 3 and 7 weeks postoperation and tended to last at least 1-2 weeks after landing (Fig. 6). Limb regenerates from animals that were

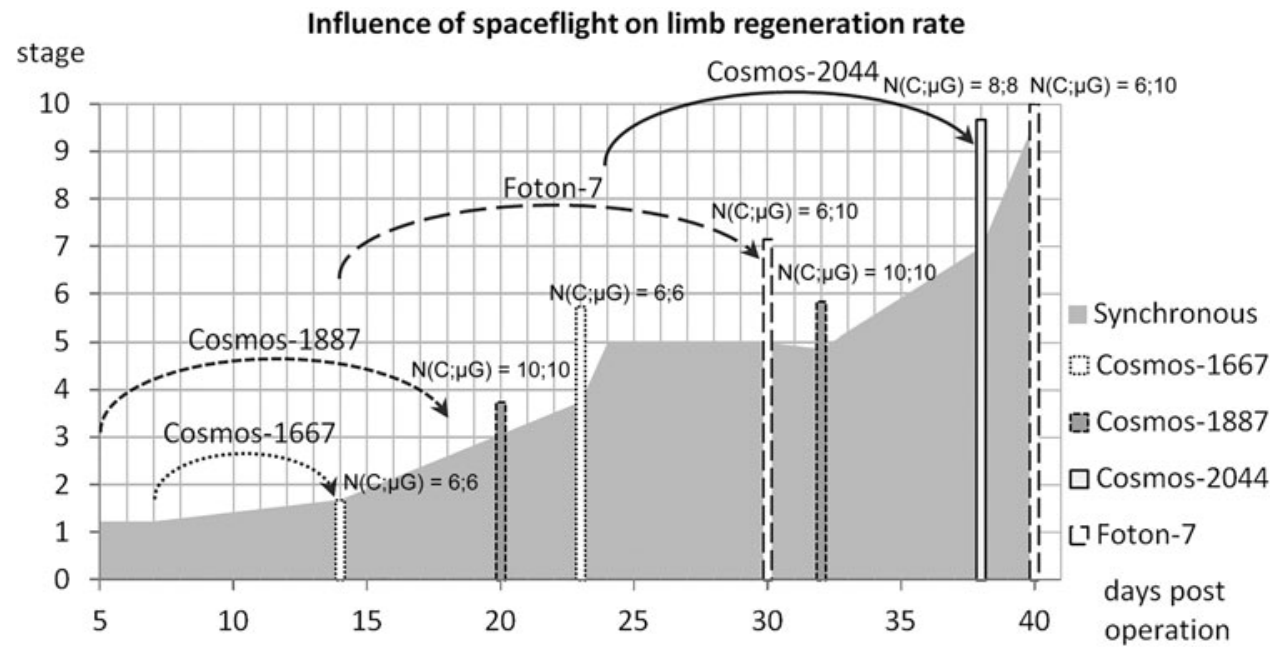

FIG. 6. Acceleration of limb regeneration by spaceflight (summarized data from four experiments). $\mathrm{N}(\mathrm{C} ; \mu \mathrm{G})$ indicates sample sizes in controls and microgravity groups, respectively. 
FIG. 7. Proliferation rates of blastemal cells in limb regenerates of similar stages during Foton-7 spaceflight experiment. $\left[{ }^{3} \mathrm{H}\right]$-thymidinelabeled cells were counted in every second section over a complete series and summarized to get an individual sample's value; six samples per group were analyzed.

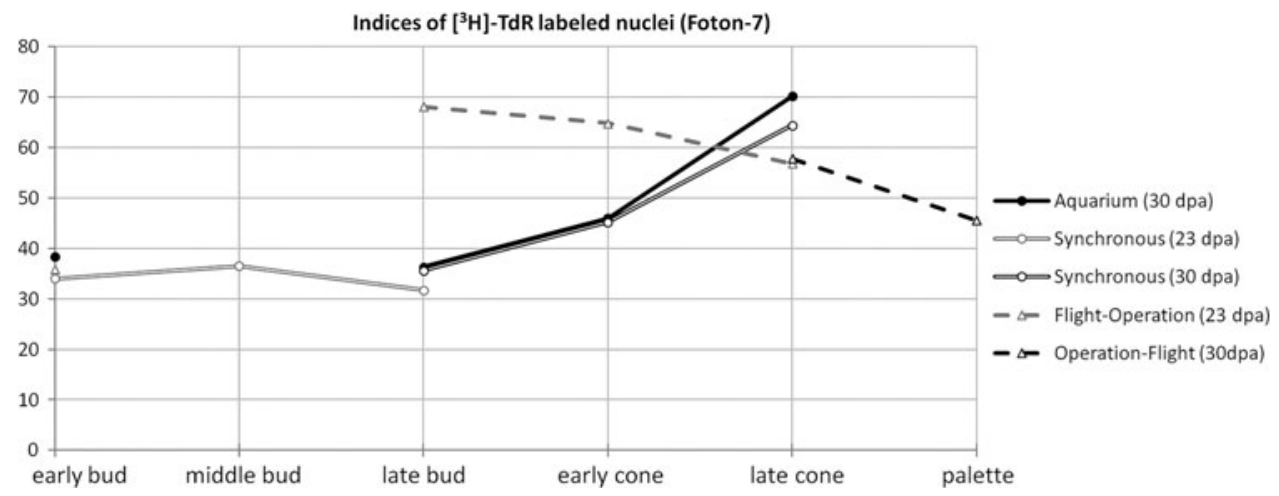

subjected to spaceflight during early stages of regeneration or even before the amputation itself were more developed than in $1 \mathrm{~g}$ synchronous and aquarium control [52,53,59,128131]. Another trend noticed in these experiments was synchronization of regeneration: The range of stages reached by individual regenerates within a group grew over time in synchronous control, but it was much smaller and decreased over time in spaceflight groups of animals. Interestingly, the stimulating effect of microgravity was evident even when limb amputation was performed after landing, suggesting that long-term alterations in cellular states are imposed by spaceflight $[53,56,59]$. Rare abnormalities in limb regeneration, which were noted in some experiments [53], tended to be moderate-for example, fusion of finger skin-and also occurred in controls.

Pleurodeles waltl tail regeneration seems to be less affected by spaceflight. Tail regenerates in Bion-11 mission and simulated microgravity experiments were longer in spaceflight/clinostat than in controls, but later Foton-M2 and Foton-M3 missions [66,132] showed no prominent differences in regenerate size or stage between flight and control groups, although more subtle histological differences were noted: Spinal cord and cartilage rod seemed more mature in spaceflight. By some criteria (area normalized to basal values and regenerate thickness), flight regenerates were even a little behind the control ones in Foton-M2 flight [133]. It should be concluded that the microgravity effect on tail regeneration rate (if any) is small enough to be overridden by individual variation or nuances of measurement. During earlier joined Russian-French missions, tail regeneration in microgravity was also found to proceed normally, with few histological changes from control: curves and local thickenings of wound epidermis, and also increased pigmentation of blastema due to higher numbers of melanocytes and melanophores [134,135].

To separate microgravity from other spaceflight factors, we conducted several experiments with simulated microgravity, using two different clinostats and two newt species- $P$. waltl and Triturus vulgaris. Both limb and tail regeneration were assessed, and results largely replicated our findings from spaceflight experiments [57,136], with certain species-specific differences, thus confirming the leading role of microgravity in observed effects.

In view of accelerated regeneration in spaceflight, it was logical to compare cellular proliferation between spaceflight and ground conditions. Such attempts were made in all flights by different means, from $\left[{ }^{3} \mathrm{H}\right]-\mathrm{TdR}$ injections performed after landing in early years to specially developed hardware for continuous BrdU delivery during later spaceflights [137]. It was repeatedly reported that proliferation indices were higher in limb regenerates after spaceflight than in synchronous control [52,56,129,131].

The comparisons, however, have often been hindered by differences in stage acquired by regenerates in different groups by fixation. In Foton-7 flight, the data were normalized by the limb regenerate stage [59]. Synchronous and aquarium control regenerates demonstrated almost identical proliferation dynamics (indices of $\left[{ }^{3} \mathrm{H}\right]-\mathrm{TdR}$ labeled nuclei), and similar values were obtained in late bud synchronous control limbs from different amputation schedules, which speaks for the validity of the data. Proliferation rate during blastema accumulation (late bud-early cone stages) was increased 1.5-2.0-fold compared with controls (Fig. 7).

Although first attempts to estimate cell proliferation indices in tail regenerates failed, later studies showed that spaceflight caused $\sim 1.5$-fold increase in BrdU incorporation within epidermis, blastema, and melanophores, and 2fold increase in the transitional zone between stump and regenerate to control [132]. Dividing cells were also more likely to be found in groups in spaceflight regenerates, and as individual cells in control. Ependyma cells, especially at the apical level, which actively elongates the remaining spinal cord [138], also stained more densely in spaceflight [66].

Taken together, our results indicate that microgravity supports and, depending on the system, accelerates proliferation of stem-like blastema cells in newt. This effect is more prominent during limb regeneration, which could at least partially account for the significant increase in regenerate's outgrowth in microgravity, which is seen during limb, but not tail regeneration.

Tissue regeneration of muscles. Valuable insights into the behavior of stem-like blastemal cells during regeneration in microgravity were acquired in Foton-7 spaceflight experiment comparing different modes of muscle regeneration: tissue regeneration of minced muscle versus epimorphic regeneration after limb amputation [53]. Although epimorphic regeneration proceeded faster in spaceflight than in synchronous control, the opposite was true for muscle tissue regeneration. On day 30 after mincing, "spaceflown" muscles contained strands of myoblasts oriented along the tension axis, with occasional formation of nonstriated myotubules; muscles in synchronous control contained newly formed fibers along with such myotubules.

In the same spaceflight, microgravity was shown to have the same deleterious effect on intact newt muscles that it has 


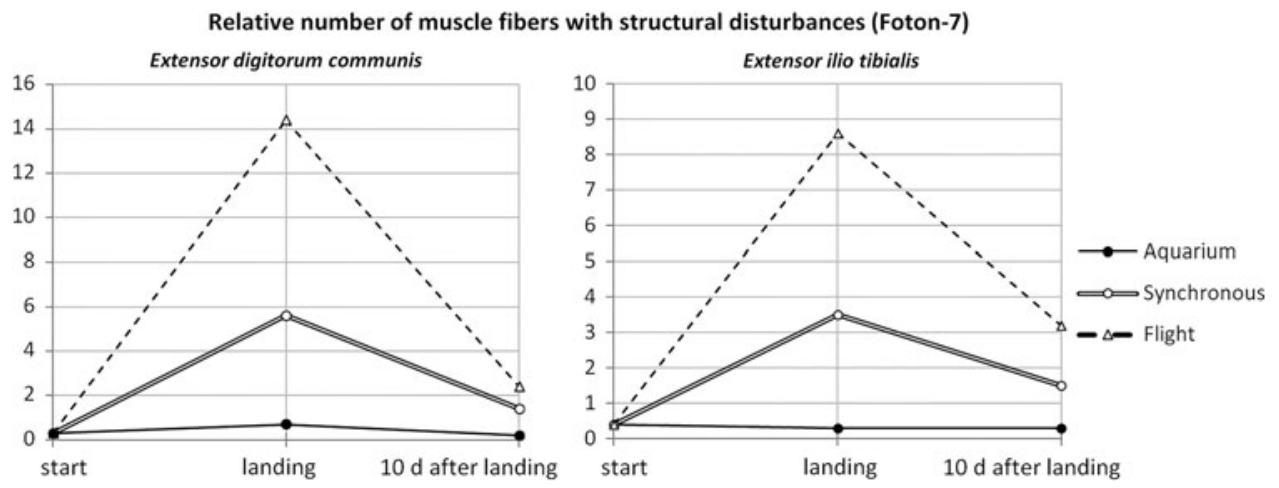

FIG. 8. Changes in intact newt muscle organization after a 16-day long spaceflight onboard Foton-7 satellite. Percentage of muscle abnormalities were counted on serial sections for six animals per group. on mammalian ones. On landing, muscles appeared edematous, muscle fibers became rounded, strata of endomysium thickened, myofibrils became thin, broken and interspaced with gaps, or even absent-in other words, typical muscular atrophy took place. Interestingly, it also happened in synchronous control (although to a lesser extent) when compared with aquarium control (Fig. 8). In all cases, muscle atrophy was significantly, but not completely reduced 10 days after landing.

These results may hold the key to many questions raised by spaceflight studies: poor tissue regeneration compared with superb epimorphic regeneration in microgravity, prolonged action of spaceflight that is evident even if amputation was performed after landing, and differences between limb and tail in terms of susceptibility to spaceflight. Spaceflight leads to disassembling of muscle fibers in general, which in case of intact muscles manifests as atrophy. However, during epimorphic regeneration, it facilitates the enrolling process of muscle dedifferentiation, which is a major contributor to limb blastema [139]. Even if amputation takes place after landing, the effect should be present as long as muscle atrophy has not been completely healed. On the contrary, disassembling of muscle fibers in healing minced muscles is counterproductive, as tissue regeneration proceeds through activation of resident adult stem cells (postsatellite cells) and does not rely on muscle dedifferentiation as a cell source [140-144]-hence the retardation effect. Finally, newt tail regeneration is considered to be different from limb regeneration, being less dependent on muscle dedifferentiation, and more dependent on stem cells as a source of blastema [111,145-147], so microgravity should not have such a strong accelerating effect on tail regeneration. This conclusion is in agreement with our data from Foton-M2 and Foton-M3 missions, where tail regenerates from spaceflight group were similar to synchronous control in size or stage of regeneration $[66,132]$.

\section{Discussion}

Multiple experiments using different animal models have shown that cell proliferation, growth, differentiation, signaling, shape, and gene expression are all affected by altered gravity (reviewed in Ref. [148,149]). We studied microgravity influence on several newt regenerating systems in vivo, focusing on the behavior of stem-like cells that provide a cellular source of regeneration, and demonstrated that they maintain their primary features and remain func- tional in microgravity. It is in concordance with our data from 30-day long spaceflight onboard Russian biosatellite Bion-M1 (Russia, 2013), where we performed immunochemical and molecular analyses of murine muscles. Despite the general negative effect on muscle structure, microgravity did not prevent activation of satellite cells (mammalian muscle tissue-specific stem cells [150]) and onset of regenerative response [29]. We can conclude that our results are not species specific, but they rather reflect the general ability of vertebrate stem and stem-like cells in vivo to maintain their regeneration potential in microgravitywhich is also important for human studies.

Microgravity's most prominent effect on newt stem-like cells in vivo is stimulation of proliferation, observed in almost all newt regenerating systems. We do not know whether it is achieved by speeding up cell divisions or by prompting more cells to enter the cell cycle; the latter could explain the increased size of lens regenerates, which usually differentiate after 6-7 divisions of source cells [151,152]. In most cases, increased proliferation was beneficial, leading to a more rapid regeneration, although in rare cases it caused morphological abnormalities. In addition, depending on the system, microgravity promoted dedifferentiation (and acquisition of stem-like status) or differentiation of cells de novo within the maturing regenerate. Microgravity's action could be summarized as quantitative modulation of stemlike cells' primary behaviors without gross interruption of their functioning.

We speculate that microgravity induces nonspecific, whole-organism response that interplays with local processes and leads to different outcomes depending on their specifics. Local regulatory mechanisms that govern proliferation and differentiation of stem-like cells in normal conditions, and are likely to be affected in microgravity, are presented in respective chapters. Systemic changes could include those in hormonal status, blood composition, and immune system. Indeed, in $P$. waltl, spaceflight increased free $\mathrm{Ca}^{2+}$ levels in plasma (which led to intense calcitonin secretion from the ultimobrachial gland and gradual depletion of its tissue) [54] and caused immune system deregulation: altered proportions of leukocytes and immunoglobulins, modified expression of genes encoding variable domains of IgM heavy-chains, and reduced somatic hypermutation [153]. There are multiple ways of linking these global responses to local regulatory mechanisms (reviewed in Ref. [82]).

One of the possible links between systemic and local microgravity effects is epigenetic regulation. It is being 
extensively studied in recent years in the context of many cellular processes, and evidence begins to accumulate that it is also sensitive to external factors such as gravitational loading. For example, DNA methylation is important for myogenic differentiation in normal conditions-DNAdemethylating agent 5-azacytidine upregulates $M y o D$ expression and induces myogenesis [154]—so it increases the methylation of myogenesis genes, such as Myodl, which takes place in simulated microgravity [155], and it might account for inhibited myoblast differentiation in these conditions [156]. Ogneva et al. reported increased total methylation level in mice after 30 days of spaceflight and decreased the amount of cytosine demethylase Tet 2 transcripts [157]. It could simultaneously lead to many unrelated and potentially tissue-specific effects. For example, in hearts and lungs of aforementioned mice, increased methylation was proposed as a mechanism behind changes in the expression of cytoskeleton genes.

Responses to altered gravity, from gene expression to morphological aberrations, depend on site (as we have demonstrated earlier) and developmental stage, with different sensitive "ontogenetic windows" for each structure $[158,159]$, and sometimes on gender [160]. As a general rule, cells are more sensitive to altered gravity if they are in a nonsteady state-actively cycling, changing their differentiation status, participating in some developmental process, or naturally labile (such as immune cells). Stem and stem-like cells activated by the onset of regeneration are in this category. In our experiments, exposure to microgravity was usually scheduled at the beginning of dedifferentiation and stem-like cell proliferation; different effects (or no effect) might be observed at other stages. When microgravity was applied beforehand, changes in cell behavior compared with $1 \mathrm{~g}$ control only occurred during the active proliferation phase in response to operation, marking it as a sensitive stage.

It is interesting to consider another spectacular example of spaceflight's lasting effect-spontaneous transition to double-headed phenotype in regenerating planaria, which is maintained through subsequent dissections long after landing. Planarian regeneration relies on activation of stem cells, neoblasts, so this effect is likely to be mediated by changes in their biology — cytoskeleton structure, bioelectrical circuits, or Wnt signaling [28]. Comparison with such models could bring insights regarding the universality of the mechanisms mediating microgravity influence on stem-like cells.

\section{Conclusion}

Decades of studying the in vivo behavior of newt stemlike cells, which provide a source for regeneration, under conditions of real and simulated microgravity demonstrated susceptibility of cell proliferation, differentiation, and conversion to gravity influence.

IPECs, RPECs, eye growth zone cells, and MG (all possessing stem-like qualities in lower vertebrates) proliferate more intensely in microgravity. This effect is lasting and can be observed even weeks after exposure. We suggest that it is mediated by systemic changes affecting local regulatory mechanisms, such as Fgf, Wnt, and Hsp signaling pathways.

Intense proliferation of iris and retina pigmented epithelium cells is followed by fast differentiation, leading to accelerated formation of lens and retina regenerates in microgravity and increased size of the former. Intense proliferation of MG leads to reactive gliosis - amplification of this cellular population serving protective functions in stressful conditions (such as increased intraocular pressure in microgravity).

Increased proliferation is also evident in stem-like blastema cells during newt limb regeneration in microgravity. At the same time, newt muscles seem to disassemble in weightlessness, just as mammalian muscles do. Depending on the context, this process can lead to muscle atrophy (in intact tissue), hinder tissue regeneration (in minced muscle model), and boost epimorphic regeneration (in systems, where regeneration depends on muscle dedifferentiation as a cell source, such as limb).

Increased cell proliferation in studied in vivo models has mostly been beneficial for regeneration outcome, but we have detected rare cases of morphological aberrations in newly formed eyes, limbs, and tails, presumably due to over-proliferation of stem-like cells.

These results, obtained for different regenerating structures in newts, are relevant for both stem cells research (usually lacking possibilities for in vivo analysis) and gravitational biology, and they allow further investigation of underlying molecular mechanisms.

\section{Acknowledgments}

This work was financially supported and conducted within the framework of State Assignment for the Koltzov Institute of Developmental Biology, Russian Academy of Sciences, project no. 0108-2018-0003.

\section{Author Disclosure Statement}

No competing financial interests exist.

\section{References}

1. Meyers VE, M Zayzafoon, SR Gonda, WE Gathings and JM McDonald. (2004). Modeled microgravity disrupts collagen I/integrin signaling during osteoblastic differentiation of human mesenchymal stem cells. J Cell Biochem 93:697-707.

2. Zayzafoon M, WE Gathings and JM McDonald. (2004). Modeled microgravity inhibits osteogenic differentiation of human mesenchymal stem cells and increases adipogenesis. Endocrinology 145:2421-2432.

3. Yuge L, T Kajiume, H Tahara, Y Kawahara, C Umeda, R Yoshimoto, S-L Wu, K Yamaoka, M Asashima, K Kataoka and T Ide. (2006). Microgravity potentiates stem cell proliferation while sustaining the capability of differentiation. Stem Cells Dev 15:921-929.

4. Wang HC, ZY Zhang and WG Xin. (2007). Microgravity resulted from 3D dynamic culture induces compounding of bone morrow-derived mesenchymal stem cells with Pluronic F-127 scaffold used for repairing of cartilage defects. Chin Tissue Eng Clin Recov 11:2609-2613.

5. Chen J, R Liu, Y Yang, J Li, X Zhang, J Li, Z Wang and J Ma. (2011). The simulated microgravity enhances the differentiation of mesenchymal stem cells into neurons. Neurosci Lett 505:171-175.

6. Zhang C, L Li, J Chen and J Wang. (2015). Behavior of stem cells under outer-space microgravity and groundbased microgravity simulation. Cell Biol Int 39:647-656.

7. Blaber EA, H Finkelstein, N Dvorochkin, KY Sato, R Yousuf, BP Burns, RK Globus and EAC Almeida. (2015). 
Microgravity reduces the differentiation and regenerative potential of embryonic stem cells. Stem Cells Dev 24: 2605-2621.

8. Grimm D, M Wehland, J Pietsch, G Aleshcheva, P Wise, J van Loon, C Ulbrich, NE Magnusson, M Infanger and J Bauer. (2014). Growing tissues in real and simulated microgravity: new methods for tissue engineering. Tissue Eng Part B Rev 20:555-566.

9. Ulbrich C, M Wehland, J Pietsch, G Aleshcheva, P Wise, J Van Loon, N Magnusson, M Infanger, J Grosse, et al. (2014). The impact of simulated and real microgravity on bone cells and mesenchymal stem cells. Biomed Res Int 2014:1-15.

10. Pani G, M Verslegers, R Quintens, N Samari, L De SaintGeorges, P Van Oostveldt, S Baatout and MA Benotmane. (2016). Combined exposure to simulated microgravity and acute or chronic radiation reduces neuronal network integrity and survival. PLoS One 11:e0155260.

11. Shinde V, S Brungs, M Henry, L Wegener, H Nemade, T Rotshteyn, A Acharya, C Baumstark-Khan, CE Hellweg, et al. (2016). Simulated microgravity modulates differentiation processes of embryonic stem cells. Cell Physiol Biochem 38:1483-1499.

12. Wang Y, L An, Y Jiang and H Hang. (2011). Effects of simulated microgravity on embryonic stem cells. PLoS One 6:e29214.

13. Ohnishi T. (2016). Life science experiments performed in space in the ISS/Kibo facility and future research plans. J Radiat Res 57:i41-i46.

14. Jha R, Q Wu, M Singh, MK Preininger, $P$ Han, G Ding, HC Cho, H Jo, KO Maher, MB Wagner and C Xu. (2016). Simulated microgravity and 3D culture enhance induction, viability, proliferation and differentiation of cardiac progenitors from human pluripotent stem cells. Sci Rep 6: 30956.

15. Cui Y, J Han, Z Xiao, Y Qi, Y Zhao, B Chen, Y Fang, S Liu, X Wu and J Dai. (2018). Systematic analysis of mRNA and miRNA expression of 3D-cultured Neural Stem Cells (NSCs) in spaceflight. Front Cell Neurosci 11:434.

16. Zhang L, X Han, X Cheng, XF Tan, HY Zhao and XH Zhang. (2016). Denervated hippocampus provides a favorable microenvironment for neuronal differentiation of endogenous neural stem cells. Neural Regen Res 11:597-603.

17. Grigoriev AI, V Oganov, A Bakulin, V Poliakov, L Voronin, V Morgun, V Shnăder, L Murashko, V Novikov, A LeBlank and L Shakleford. (1998). Clinical and physiological evaluation of bone changes among astronauts after long-term space flights. Aviakosm Ekol Med 32:21-25.

18. Vico L, P Collet, A Guignandon, MH Lafage-Proust, T Thomas, M Rehailia and C Alexandre. (2000). Effects of long-term microgravity exposure on cancellous and cortical weight-bearing bones of cosmonauts. Lancet 355: 1607-1611.

19. Wang B, S Zhang and X Wu. (2003). Effects of microgravity on the gene expression and cellular functions of osteoblasts. Hang Tian Yi Xue Yu Yi Xue Gong Cheng Sp Med Med Eng 16:227-230.

20. Zhang X, Y Nan, H Wang, J Chen, N Wang, J Xie, J Ma and $Z$ Wang. (2013). Model microgravity enhances endothelium differentiation of mesenchymal stem cells. Naturwissenschaften 100:125-133.

21. Blaber EA, N Dvorochkin, ML Torres, R Yuosuf, BP Burns, RK Globus and EAC Almeida. (2014). Mechanical unloading of bone in microgravity reduces mesenchymal and hematopoietic stem cell-mediated tissue regeneration. Stem Cell Res 13:181-201.

22. Luna C, AG Yew and AH Hsieh. (2015). Effects of angular frequency during clinorotation on mesenchymal stem cell morphology and migration. Npj Microgravity 1: 15007.

23. Mao X, Z Chen, Q Luo, B Zhang and G Song. (2016). Simulated microgravity inhibits the migration of mesenchymal stem cells by remodeling actin cytoskeleton and increasing cell stiffness. Cytotechnology 68:2235-2243.

24. Wang N, H Wang, J Chen, X Zhang, J Xie, Z Li, J Ma, W Wang and Z Wang. (2014). The simulated microgravity enhances multipotential differentiation capacity of bone marrow mesenchymal stem cells. Cytotechnology 66: 119-131.

25. Huang Y, Z-Q Dai, S-K Ling, H-Y Zhang, Y-M Wan and Y-H Li. (2009). Gravity, a regulation factor in the differentiation of rat bone marrow mesenchymal stem cells. $\mathbf{J}$ Biomed Sci 16:87.

26. Xue L, Y Li and J Chen. (2017). Duration of simulated microgravity affects the differentiation of mesenchymal stem cells. Mol Med Rep 15:3011-3018.

27. Bradamante S, L Barenghi and JA Maier. (2014). Stem cells toward the future: the space challenge. Life 4:267280.

28. Morokuma J, F Durant, KB Williams, JM Finkelstein, DJ Blackiston, T Clements, DW Reed, M Roberts, M Jain, et al. (2017). Planarian regeneration in space: persistent anatomical, behavioral, and bacteriological changes induced by space travel. Regen (Oxford, England) 4:85102.

29. Radugina EA, EAC Almeida, EA Blaber, VA Poplinskaya, YV Markitantova and EN Grigoryan. (2018). Exposure to microgravity for 30 days onboard Bion M1 caused muscle atrophy and impaired regeneration in murine femoral Quadriceps. Life Sci Sp Res 16:18-25.

30. Snijders T, JP Nederveen, BR McKay, S Joanisse, LB Verdijk, LJC van Loon and G Parise. (2015). Satellite cells in human skeletal muscle plasticity. Front Physiol 6: 283.

31. Martin TP, VR Edgerton and RE Grindeland. (1988). Influence of spaceflight on rat skeletal muscle. J Appl Physiol 65:2318-2325.

32. Ohira Y, B Jiang, RR Roy, V Oganov, E Ilyina-Kakueva, JF Marini and VR Edgerton. (1992). Rat soleus muscle fiber responses to 14 days of spaceflight and hindlimb suspension. J Appl Physiol 73:51S-57S.

33. Allen DL, JK Linderman, RR Roy, AJ Bigbee, RE Grindeland, V Mukku and VR Edgerton. (1997). Apoptosis: a mechanism contributing to remodeling of skeletal muscle in response to hindlimb unweighting. Am J Physiol 273: C579-C587.

34. Shenkman BS, OV Turtikova, TL Nemirovskaya and AI Grigoriev. (2010). Skeletal muscle activity and the fate of myonuclei. Acta Naturae 2:59-66.

35. Shenkman BS. (2016). From slow to fast: hypogravityinduced remodeling of muscle fiber myosin phenotype. Acta Naturae 8:47-59.

36. Yamada T. (1977). Control mechanisms in cell-type conversion in newt lens regeneration. Monogr Dev Biol 13:1-126.

37. Eguchi G. (1988). Cellular and molecular background of Wolffian lens regeneration. Cell Differ Dev 25:147-158. 
38. Del Rio-Tsonis K and PA Tsonis. (2003). Eye regeneration at the molecular age. Dev Dyn 226:211-224.

39. Henry JJ and PA Tsonis. (2010). Molecular and cellular aspects of amphibian lens regeneration. Prog Retin Eye Res 29:543-555.

40. Eguchi G. (1964). Electron microscopic studies on lens regeneration. Embryologia (Nagoya) 8:247-287.

41. Eguchi G. (1963). Electron microscopic studies on lens regeneration. Embryologia (Nagoya) 8:45-62.

42. Tsonis PA. (2000). Regeneration in vertebrates. Dev Biol 221:273-284.

43. Tsonis PA and K Del Rio-Tsonis. (2004). Lens and retina regeneration: transdifferentiation, stem cells and clinical applications. Exp Eye Res 78:161-172.

44. Takahashi K, K Tanabe, M Ohnuki, M Narita, T Ichisaka, $\mathrm{K}$ Tomoda and S Yamanaka. (2007). Induction of pluripotent stem cells from adult human fibroblasts by defined factors. Cell 131:861-872.

45. Maki N, R Suetsugu-Maki, H Tarui, K Agata, K Del RioTsonis and PA Tsonis. (2009). Expression of stem cell pluripotency factors during regeneration in newts. Dev Dyn 238:1613-1616.

46. Maki N, PA Tsonis and K Agata. (2010). Changes in global histone modifications during dedifferentiation in newt lens regeneration. Mol Vis 16:1893-1897.

47. Maki N, K Takechi, S Sano, H Tarui, Y Sasai and K Agata. (2007). Rapid accumulation of nucleostemin in nucleolus during newt regeneration. Dev Dyn 236:941-950.

48. Tsai RYL and RDG McKay. (2002). A nucleolar mechanism controlling cell proliferation in stem cells and cancer cells. Genes Dev 16:2991-3003.

49. Donaldson DJ and F Chan. (1973). The influence of temperature on lens regeneration in the adult newt, Triturus Viridescens. Growth 37:69-76.

50. Michel C and T Yamada. (1974). Cellular studies of X-ray induced inhibition of lens regeneration. Differentiation 2: 193-201.

51. Okamoto T, T Kanao, Y Miyachi and N Nohara. (2004). Marked increase in the rate of ocular lens regeneration in the newt, Cynops pyrrhogaster, following partial body exposure to low dose X-rays. Br J Radiol 77:49-51.

52. Mitashov VI, EN Grigoryan, SY Tuchkova, EA Oigenblick and IE Malchevskaya. (1987). Regeneration in amphibia under the space flight conditions. Cell Differ Dev 27:230.

53. Brushlinskaya NV, EN Grigoryan, SY Tuchkova, HJ Anton and VI Mitashov. (1997). [Organ and tissue regeneration in lower vertebrate animals during space flight and after its completion]. Ontogenez 28:198-210.

54. Brushlinskaya NV, SY Tuchkova, EN Grigoryan, HJ Anton and VI Mitashov. (1994). [The characteristics of the effect of space flight factors on regeneration processes in mammals and Urodela]. Izv Akad Nauk Seriia Biol 4:667-676.

55. Brushlinskaya NV. (1995). [The effect of space flight factors on the cellular proliferative activity of different eye tissues during lens regeneration in the Spanish newt Pleurodeles waltlii]. Izv Akad Nauk Seriia Biol 149-156.

56. Tuchkova SY, NV Brushlinskaia, EN Grigoryan and VI Mitashov. (1994). [The comparative characteristics of crystalline lens and limb regeneration in newts operated on before and after the completion of an orbital space flight]. Izv Akad Nauk Seriia Biol 6:859-869.

57. Anton HJ, EN Grigoryan and VI Mitashov. (1996). Influence of longitudinal whole animal clinorotation on lens, tail, and limb regeneration in urodeles. Adv Space Res 17: 55-65.

58. Oviedo NJ and WS Beane. (2009). Regeneration: the origin of cancer or a possible cure? Semin Cell Dev Biol 20: 557-564.

59. Mitashov VI, NV Brushlinskaya, EN Grigoryan, SY Tuchkova and HJ Anton. (1996). Regeneration of organs and tissues in lower vertebrates during and after space flight. Adv Space Res 17:241-255.

60. Grigoryan EN, HJ Anton and VI Mitashov. (2006). Real and simulated microgravity can activate signals stimulating cells to enter the $\mathrm{S}$ phase during lens regeneration in urodelean amphibians. Adv Sp Res 38:1071-1078.

61. Kimura Y, M Madhavan, MK Call, W Santiago, PA Tsonis, JD Lambris and K Del Rio-Tsonis. (2003). Expression of complement 3 and complement 5 in newt limb and lens regeneration. J Immunol 170:2331-2339.

62. Hayashi T, N Mizuno and H Kondoh. (2008). Determinative roles of FGF and Wnt signals in iris-derived lens regeneration in newt eye. Dev Growth Differ 50:279-287.

63. Tsonis PA, MN Vergara, JR Spence, M Madhavan, EL Kramer, MK Call, WG Santiago, JE Vallance, DJ Robbins and K Del Rio-Tsonis. (2004). A novel role of the hedgehog pathway in lens regeneration. Dev Biol 267:450-461.

64. McDevitt DS, SK Brahma, Y Courtois and JC Jeanny. (1997). Fibroblast growth factor receptors and regeneration of the eye lens. Dev Dyn 208:220-226.

65. Del Rio-Tsonis K, JC Jung, IM Chiu and PA Tsonis. (1997). Conservation of fibroblast growth factor function in lens regeneration. Proc Natl Acad Sci U S A 94:1370113706.

66. Grigoryan EN, VA Poplinskaya, EI Domaratskaya, YP Novikova, KS Aleinikova, N Dvorochkin and EAC Almeida. (2008). Tissue regeneration in Urodela on FotonM3. J Gravitational Physiol 15:277-280.

67. Heikkila JJ. (2010). Heat shock protein gene expression and function in amphibian model systems. Comp Biochem Physiol A Mol Integr Physiol 156:19-33.

68. Grigoryan EN, N Dvorochkin, VA Poplinskaya, R Yuosuf, EA Radugina and EAC Almeida. (2017). The effect of hypergravity on the lens, cornea and tail regeneration in Urodela. Acta Astronaut 138:423-433.

69. Fuhrmann S, CJ Zou and EM Levine. (2014). Retinal pigment epithelium development, plasticity, and tissue homeostasis. Exp Eye Res 123:141-150.

70. Stroeva OG and VI Mitashov. (1983). Retinal pigment epithelium: proliferation and differentiation during development and regeneration. Int Rev Cytol 83:221-293.

71. Mitashov VI. (1997). Retinal regeneration in amphibians. Int J Dev Biol 41:893-905.

72. Chiba C and VI Mitashov. (2007). Cellular and molecular events in the adult newt retinal regeneration. In: Strategies for Retinal Tissue Repair and Regeneration in Vertebrates: From Fish to Human. Chiba C, ed. Research Signpost, Kerala, pp 15-33.

73. Lamba D, M Karl and T Reh. (2008). Neural regeneration and cell replacement: a view from the eye. Cell Stem Cell 2:538-549.

74. Grigoryan EN and YV Markitantova. (2016). Cellular and molecular preconditions for Retinal Pigment Epithelium (RPE) natural reprogramming during retinal regeneration in Urodela. Biomedicines 4:E28.

75. Markitantova YV, PP Avdonin and EN Grigoryan. (2015). [Identification of the gene encoding nucleostemin in the 
eye tissues of Pleurodeles waltl]. Izv Akad Nauk Seriia Biol 5:453-460.

76. Luz-Madrigal A, E Grajales-Esquivel, A McCorkle, AM DiLorenzo, K Barbosa-Sabanero, PA Tsonis and K Del Rio-Tsonis. (2014). Reprogramming of the chick retinal pigmented epithelium after retinal injury. BMC Biol 12:28.

77. Stone LS. (1960). Regeneration of the lens, iris, and neural retina in a vertebrate eye. Yale J Biol Med 32:464-473.

78. Grigoryan EN, VI Mitashov and HJ Anton. (2002). Urodelean amphibians in studies on microgravity: effects upon organ and tissue regeneration. Adv Sp Res 30:757-764.

79. Grigoryan EN, HJ Anton and VI Mitashov. (1998). Microgravity effects on neural retina regeneration in the newt. Adv Sp Res 22:293-301.

80. Grigoryan EN and HJ Anton. (1994). Specific features of eye regeneration after detachment of the retina in the newt induced by gravity changes in a clinostat. Biol Bull 3:342-352.

81. DiStefano T, HY Chen, C Panebianco, KD Kaya, MJ Brooks, L Gieser, NY Morgan, T Pohida and A Swaroop. (2018). Accelerated and improved differentiation of retinal organoids from pluripotent stem cells in rotatingwall vessel bioreactors. Stem Cell Rep 10:300-313.

82. Grigoryan EN. (2018). Molecular factors of the maintenance and activation of the juvenile phenotype of cellular sources for eye tissue regeneration. Biochemistry (Moscow) 83:1627-1642.

83. de Hoz R, B Rojas, AI Ramírez, JJ Salazar, BI Gallego, A Triviño and JM Ramírez. (2016). Retinal macroglial responses in health and disease. Biomed Res Int 2016:1-13.

84. Lenkowski JR and PA Raymond. (2014). Müller glia: stem cells for generation and regeneration of retinal neurons in teleost fish. Prog Retin Eye Res 40:94-123.

85. Goldman D. (2014). Müller glial cell reprogramming and retina regeneration. Nat Rev Neurosci 15:431-442.

86. Hamon A, JE Roger, XJ Yang and M Perron. (2016). Müller glial cell-dependent regeneration of the neural retina: an overview across vertebrate model systems. Dev Dyn 245:727-738.

87. Jorstad NL, MS Wilken, WN Grimes, SG Wohl, LS Vandenbosch, T Yoshimatsu, RO Wong, F Rieke and TA Reh. (2017). Stimulation of functional neuronal regeneration from Müller glia in adult mice. Nature 548:103-107.

88. Giannelli SG, GC Demontis, G Pertile, P Rama and V Broccoli. (2011). Adult human Müller glia cells are a highly efficient source of rod photoreceptors. Stem Cells 29:344-356.

89. Bringmann A, T Pannicke, J Grosche, M Francke, P Wiedemann, SN Skatchkov, NN Osborne and A Reichenbach. (2006). Müller cells in the healthy and diseased retina. Prog Retin Eye Res 25:397-424.

90. Roesch K, AP Jadhav, JM Trimarchi, MB Stadler, B Roska, BB Sun and CL Cepko. (2008). The transcriptome of retinal Müller glial cells. J Comp Neurol 509:225-238.

91. Powell C, AR Grant, E Cornblath and D Goldman. (2013). Analysis of DNA methylation reveals a partial reprogramming of the Muller glia genome during retina regeneration. Proc Natl Acad Sci 110:19814-19819.

92. Raymond PA, LK Barthel, RL Bernardos and JJ Perkowski. (2006). Molecular characterization of retinal stem cells and their niches in adult zebrafish. BMC Dev Biol 6:36.

93. Ramachandran R, BV Fausett and D Goldman. (2010). Asclla regulates Müller glia dedifferentiation and retinal regeneration through a Lin-28-dependent, let-7 microRNA signalling pathway. Nat Cell Biol 12:1101-1107.
94. Phillips JM and DC Otteson. (2011). Differential expression of neuronal genes in Müller glia in two- and threedimensional cultures. Investig Opthalmology Vis Sci 52: 1439.

95. Grigoryan EN, VA Poplinskaya and YP Novikova. (2016). Retinal remodeling under conditions of organotypic $3 \mathrm{D}$ culturing in vitro and after damage in vivo in lower and higher vertebrates. New Front Ophthalmol 2, DOI:10.15761/NFO.1000118.

96. Novikova YP, KS Aleinikova, MS Krasnov, VA Poplinskaya and EN Grigoryan. (2010). In vitro organotypic cultivation of adult newt and rat retinas. Biol Bull 37:327338.

97. Grigoryan EN, HJ Anton, VA Poplinskaya, KS Aleinikova, EI Domaratskaya, YP Novikova and EAC Almeida. (2012). Signs of Müller cell gliotic response found in the retina of newts exposed to real and simulated microgravity. Adv Sp Res 49:1465-1471.

98. Grigoryan EN, SY Tuchkova, VA Poplinskaya and VI Mitashov. (1999). [Retinal regeneration after dissection of the optic nerve in newts exposed on board the Bion-11 biosatellite]. Aviakosm Ekolog Med 33:15-20.

99. Lam TT, JMK Kwong and MOM Tso. (2003). Early glial responses after acute elevated intraocular pressure in rats. Investig Opthalmol Vis Sci 44:638-645.

100. Kuzmin MP. (1984). Circulation of the blood in the eye retina and intraocular pressure of the human under conditions of simulated weightlessness. In: Kosmicheskaya Antropologia: Technika I Metodi Issledovanii. Melua AI, ed. Nauka, Leningrad, pp 447-450.

101. Schwartz R, J Draeger, S Groenhoff and KD Flade. (1993). [Results of self-tonometry during the 1st GermanRussian MIR mission 1992]. Ophthalmologe 90:640-642.

102. Kroll G, J Draeger, H Brande, B Hechler, E Burchard and W Buck. (1987). Untersuchungen uber den intraocularen Druck bei rasch wechselnden g-belastungen in der ZAchse. Mitt Dtsch Ges Luft- Und Raumfahrtmed 2:10-16.

103. Lewis GP and SK Fisher. (2003). Up-regulation of glial fibrillary acidic protein in response to retinal injury: its potential role in glial remodeling and a comparison to vimentin expression. Int Rev Cytol 230:263-290.

104. Lewis GP, EA Chapin, G Luna, KA Linberg and SK Fisher. (2010). The fate of Müller's glia following experimental retinal detachment: nuclear migration, cell division, and subretinal glial scar formation. Mol Vis 16:1361-1372.

105. Ali A, PH Krone, DS Pearson and JJ Heikkila. (1996). Evaluation of stress-inducible hsp90 gene expression as a potential molecular biomarker in Xenopus laevis. Cell Stress Chaperones 1:62-69.

106. Osakada F, S Ooto, T Akagi, M Mandai, A Akaike and M Takahashi. (2007). Wnt signaling promotes regeneration in the retina of adult mammals. J Neurosci 27:4210-4219.

107. Iten LE and SV Bryant. (1976). Stages of tail regeneration in the adult newt, Notophthalmus viridescens. J Exp Zool 196:283-292.

108. Iten LE and SV Bryant. (1973). Forelimb regeneration from different levels of amputation in the newt,Notophthalmus viridescens: length, rate, and stages. Wilhelm Roux' Arch Für Entwicklungsmechanik Der Org 173:263-282.

109. Steen TP. (1970). Origin and differentiative capacities of cells in the blastema of the regenerating salamander limb. Am Zool 10:119-132.

110. Kragl M, D Knapp, E Nacu, S Khattak, M Maden, HH Epperlein and EM Tanaka. (2009). Cells keep a memory 
of their tissue origin during axolotl limb regeneration. Nature 460:60-65.

111. Morrison JI, S Lööf, P He and A Simon. (2006). Salamander limb regeneration involves the activation of a multipotent skeletal muscle satellite cell population. J Cell Biol 172:433-440.

112. Sandoval-Guzmán T, H Wang, S Khattak, M Schuez, K Roensch, E Nacu, A Tazaki, A Joven, EM Tanaka and A Simon. (2014). Fundamental differences in dedifferentiation and stem cell recruitment during skeletal muscle regeneration in two salamander species. Cell Stem Cell 14: 174-187.

113. Chiba C. (2017). [Differences in the mechanism of muscle regeneration between the larval and metamorphosed newts.]. Clin Calcium 27:345-350.

114. Liversage RA. (1991). Origin of the blastema cells in epimorphic regeneration. In: A History of Regeneration Research: Milestones in the Evolution of a Science. Dinsmore CE, ed. Cambridge University Press, Cambridge, pp 179-199.

115. Monaghan JR and M Maden. (2013). Cellular plasticity during vertebrate appendage regeneration. Curr Top Microbiol Immunol 367:53-74.

116. Tanaka EM. (2003). Cell differentiation and cell fate during urodele tail and limb regeneration. Curr Opin Genet Dev 13:497-501.

117. Burgess AM. (1967). The developmental potentialities of regeneration blastema cell nuclei as determined by nuclear transplantation. J Embryol Exp Morphol 18:27-41.

118. Carlson BM. (1972). Muscle morphogenesis in axolotl limb regenerates after removal of stump musculature. Dev Biol 28:487-497.

119. Thornton CS. (1938). The histogenesis of the regenerating fore limb of larval Amblystoma after exarticulation of the humerus. J Morphol 62:219-241.

120. Lo DC, F Allen and JP Brockes. (1993). Reversal of muscle differentiation during urodele limb regeneration. Proc Natl Acad Sci U S A 90:7230-7234.

121. Echeverri K and EM Tanaka. (2002). Ectoderm to mesoderm lineage switching during axolotl tail regeneration. Science 298:1993-1996.

122. Caubit X, JF Riou, J Coulon, J-P Arsanto, A Benraiss, JC Boucaut and YR Thouveny. (1994). Tenascin expression in developing, adult and regenerating caudal spinal cord in the urodele amphibians. Int J Dev Biol 38:661-672.

123. Gulati AK, AA Zalewski and AH Reddi. (1983). An immunofluorescent study of the distribution of fibronectin and laminin during limb regeneration in the adult newt. Dev Biol 96:355-365.

124. Asahina K, M Obara and K Yoshizato. (1999). Expression of genes of type I and type II collagen in the formation and development of the blastema of regenerating newt limb. Dev Dyn 216:59-71.

125. Géraudie J and P Ferretti. (1998). Gene expression during amphibian limb regeneration. Int Rev Cytol 180:1-50.

126. Simon HG, C Nelson, D Goff, E Laufer, BA Morgan and CJ Tabin. (1995). Differential expression of myogenic regulatory genes and Msx-1 during dedifferentiation and redifferentiation of regenerating amphibian limbs. Dev Dyn 202:1-12.

127. Rao N, D Jhamb, DJ Milner, B Li, F Song, M Wang, SR Voss, M Palakal, MW King, et al. (2009). Proteomic analysis of blastema formation in regenerating axolotl limbs. BMC Biol 7:83.
128. Mitashov VI, EN Grigoryan, SY Tuchkova and EM Cherdanzeva. (1987). Organs and tissue regeneration in amphibia under the space flight conditions. In: Proc. of the 3rd Europ. Symp. Life Science Research in Space, Graz, Austria, September 14-18, 1987. ESA SP-271. Hunt JJ, ed. ESA Publications Division, Noordwijk, pp 299-303.

129. Mitashov VI, EN Grigoryan, SY Tuchkova, EA Oigenblick and IE Malchevskaya. (1990). Lens and limb regeneration in the newt during and after 13 day long space flight. In: Proc. of the 4th Europ. Symp. Life Science Research in Space, Trieste, Italy, May 28-June 1, 1990. ESA SP-307. ESA Publications Division, Noordwijk, pp 85-92.

130. Mitashov VI, EN Grigoryan, SY Tuchkova and IE Malchevskaya. (1989). Lens and limb regeneration in amphibia under the space flight conditions. In: Recent Trends in Regeneration Research. Kiortsis V, S Koussoulakos, H Wallace, eds. Springer US, Boston, MA, pp 135-136.

131. Grigoryan EN, EA Oigenblick, SY Tuchkova, IE Malchevskaya and VI Mitashov. (1992). The influence of spaceflight factors on lens and limb regeneration in newts. In: Results of Investigations on Biosatellites. Gazenko OG, ed. Nauka, Moscow, pp 345-350.

132. Grigoryan EN, EAC Almeida, EI Domaratskaya, VA Poplinskaya, KS Aleinikova, MG Tairbekov and VI Mitashov. (2006). Experiment "Regeneration" performed aboard the russian spacecraft foton-M2 in 2005. J Gravitational Physiol 13:189-192.

133. Almeida EAC, C Roden, JA Phillips, R Yuosuf, RK Globus, N Searby, W Vercoutere, E Morey-Holton, MG Tairbekov, et al. (2006). Analysis of cell proliferation in newt (Pleurodeles waltl) tissue regeneration during spaceflight in foton M-2. J Gravitational Physiol 13:185-188.

134. Grinfeld S, F Foulquier, VI Mitashov, N Bruchlinskaia and AM Duprat. (1994). Tissue regeneration in space (spinal cord, muscle and bone) in the amphibian Pleurodeles waltl. In: Proceedings of the Fifth European Symposium on Life Sciences Research in Space ESA SP. 366. Oser H, TD Guyenne, eds. Arcachon, France, p 181.

135. Grinfeld S, F Foulquier, VI Mitashov, N Bruchlinskaia and AM Duprat. (1996). Amphibian tail regeneration in space: effect on the pigmentation of the blastema. Adv Space Res 17:237-240.

136. Anton HJ, EN Grigoryan, K Krupp-Beyerlein, H Pitzer and VI Mitashov. (1998). Influence of clinorotation and fettering stress on tail regeneration of Triturus vulgaris (Urodela). Life Sci Microgravity Res 21:1159-1162.

137. Grigoryan EN, N Dvorochkin, M Skidmore, A Howard, E Houston and EAC Almeida. (2010). Development of an animal model and spaceflight hardware to study tissue regeneration in microgravity during the foton M3 newt "Regeneration" experiment. In: 48th AIAA Aerospace Sciences Meeting Including the New Horizons Forum and Aerospace Exposition. American Institute of Aeronautics and Astronautics: Orlando, Florida, pp 2010-2737.

138. McHedlishvili L, HH Epperlein, A Telzerow and EM Tanaka. (2007). A clonal analysis of neural progenitors during axolotl spinal cord regeneration reveals evidence for both spatially restricted and multipotent progenitors. Development 134:2083-2093.

139. Echeverri K, JDW Clarke and EM Tanaka. (2001). In vivo imaging indicates muscle fiber dedifferentiation is a major contributor to the regenerating tail blastema. Dev Biol 236:151-164. 
140. Cameron JA. (1983). Regeneration of skeletal muscle in Notophthalmus viridescens. Prog Clin Biol Res 110 Pt A: 491-500.

141. Cameron JA, AR Hilgers and TJ Hinterberger. (1986). Evidence that reserve cells are a source of regenerated adult newt muscle in vitro. Nature 321:607-610.

142. Takahama H, V Mizuhira, F Sasaki and K Watanabe. (1984). Satellite cells in the tail muscles of the urodelan larvae during development. Cell Tissue Res 236:431-438.

143. Cherkasova LV. (1983). [Cell satellites and postsatellites in the muscle tissue of the adult Ambystoma mexicanum]. Dokl Akad Nauk SSSR 273:991-993.

144. Carlson BM. (2003). Muscle regeneration in amphibians and mammals: passing the torch. Dev Dyn 226:167-181.

145. Slack JMW. (2006). Amphibian muscle regenerationdedifferentiation or satellite cells? Trends Cell Biol 16:273275.

146. Thouveny YR, TE Komorowski, J-P Arsanto and BM Carlson. (1991). Early innervation of skeletal muscle during tail regeneration in urodele amphibians. J Exp Zool 260:354-370.

147. Dinsmore CE. (1981). Regulative ability of the regenerating urodele tail: the effect of unilateral soft tissue ablation. Dev Biol 82:186-191.

148. Clement JQ. (2012). Gene expression microarrays in microgravity research: toward the identification of major space genes. In: Innovations in Biotechnology. Agbo EC, ed. IntechOpen, London, pp 319-348.

149. Najrana T and J Sanchez-Esteban. (2016). Mechanotransduction as an adaptation to gravity. Front Pediatr 4:140.

150. Kawano F, Y Takeno, N Nakai, Y Higo, M Terada, $\mathrm{T}$ Ohira, I Nonaka and Y Ohira. (2008). Essential role of satellite cells in the growth of rat soleus muscle fibers. Am J Physiol Cell Physiol 295:C458-C467.

151. Mitashov VI. (1980). Patterns of mitotic cycle changes in cell transformation and regeneration in lower vertebrates. Tsitologiya 22:371-380.

152. Yamada T. (1989). Cell type expression mediated by cell cycle events, and signaled by mitogens and growth inhibitors. Int Rev Cytol 117:215-255.

153. Frippiat J-P, (2013). Contribution of the urodele amphibian Pleurodeles waltl to the analysis of spaceflightassociated immune system deregulation. Mol Immunol 56:434-441.
154. Montesano A, L Luzi, P Senesi and I Terruzzi. (2013). Modulation of cell cycle progression by 5-azacytidine is associated with early myogenesis induction in murine myoblasts. Int J Biol Sci 9:391-402.

155. Furukawa $\mathrm{T}, \mathrm{K}$ Tanimoto, $\mathrm{T}$ Fukazawa, $\mathrm{T}$ Imura, $\mathrm{Y}$ Kawahara and L Yuge. (2018). Simulated microgravity attenuates myogenic differentiation via epigenetic regulations. Npj Microgravity 4:11.

156. Torgan CE, SS Burge, AM Collinsworth, GA Truskey and WE Kraus. (2000). Differentiation of mammalian skeletal muscle cells cultured on microcarrier beads in a rotating cell culture system. Med Biol Eng Comput 38: 583-590.

157. Ogneva IV, SS Loktev and VN Sychev. (2018). Cytoskeleton structure and total methylation of mouse cardiac and lung tissue during space flight. PLoS One 13:e0192643.

158. Shimada N, G Sokunbi and SJ Moorman. (2005). Changes in gravitational force affect gene expression in developing organ systems at different developmental times. BMC Dev Biol 5:10.

159. Horn ER and M Gabriel. (2011). Gravity-related critical periods in vestibular and tail development of Xenopus laevis. J Exp Zool A Ecol Genet Physiol 315:505-511.

160. Horn ER and M Gabriel. (2014). Gender-related sensitivity of development and growth to real microgravity in Xenopus laevis. J Exp Zool A Ecol Genet Physiol 321: $1-12$.

Address correspondence to: Dr. Elena A. Radugina Koltzov Institute of Developmental Biology of Russian Academy of Sciences 26 Vavilova Street Moscow 119334 Russia

E-mail: elena.radugina@gmail.com

Received for publication November 1, 2018 Accepted after revision January 29, 2019

Prepublished on Liebert Instant Online January 30, 2019 